\begin{tabular}{|c|l|}
\hline No & \multicolumn{1}{|c|}{ Query } \\
\hline 1 & Please provide short author biographies \\
\hline 2 & $\begin{array}{l}\text { Dunn J (1989) The family as an educational environment in the pre-school years. In: } \\
\text { Desforges CW (ed.) Early Childhood Education. The British Journal of Educational } \\
\text { Psychology. Monograph Series No. 4. Edinburgh: Scottish Academic Press. - pp? }\end{array}$ \\
\hline 3 & $\begin{array}{l}\text { Gregory E (2005) In: Conteh J, Gregory E, Kearney C and Mor-Sommerfield A (eds) On } \\
\text { Writing Educational Ethnography: The Art of Collusion. Stoke-on-Trent: Trentham. - } \\
\text { chapter title and pp? }\end{array}$ \\
\hline 4 & $\begin{array}{l}\text { Gregory E, Long S and Volk D (2004) Syncretic literacy studies: Starting points. In: } \\
\text { Gregory E, Long S and Volk D (eds) Many Pathways to Literacy: Young Children Learning } \\
\text { with Siblings, Grandparents, Peers and Communities. London: Routledge - pp? }\end{array}$ \\
\hline 5 & $\begin{array}{l}\text { Nsamenang AB and Lamb ME (1998) Socialization of Nso children in the Bamenda } \\
\text { Grassfields of Northwest Cameroon. In: Woodhead M, Faulkner D and Littleton K (eds) } \\
\text { Cultural Worlds of Early Childhood. London: Routledge - pp? }\end{array}$ \\
\hline 6 & $\begin{array}{l}\text { Vygotsky LS (1981) The genesis of higher mental functions. In: Wertsch JV (ed.) The } \\
\text { Concept of Activity in Soviet Psychology. Armonk, NY: Sharpe - pp? }\end{array}$ \\
\hline 7 & $\begin{array}{l}\text { Volk D with de Acosta M (2004) Mediating networks for literacy learning; The role of } \\
\text { Puerto Rican siblings. In: Gregory E, Long S and Volk D (eds) Many Pathways to Literacy: } \\
\text { Young Children Learning with Siblings, Grandparents, Peers and Communities. London: } \\
\text { Routledge - pp? }\end{array}$ \\
\hline
\end{tabular}




\title{
The 'insider/outsider' dilemma of ethnography: Working with young children and their families in cross-cultural contexts
}

Journal of Early Childhood Research 9(2) $1-13$

(C) The Author(s) 2010 Reprints and permission: sagepub. co.uk/journalsPermissions.nav DOI: 10.1 |77//4767|8X10387899 http://ecr.sagepub.com

@SAGE

\section{Eve Gregory}

Goldsmiths, University of London, UK

\section{Mahera Ruby}

Goldsmiths, University of London, UK

\begin{abstract}
In this article we unravel the difficulty of being researchers in the homes and classrooms of children and their families whose origins are, for one of us, very different and, for the other, very similar to our own. We first situate our work within theories of early socialization and literacy teaching which underpin our understanding of how young children in cross-cultural contexts learn. We then turn to the question of working with the families and teachers of these children which poses dilemmas not explained by the theories presented.We illustrate these through a series of vignettes typifying both the 'Outsider' and the 'Insider' role. The stories highlight paradigmatic moments of complexity, clashes or collusion which we unpick in terms of their generalizability for others working in the field. Finally, we extend theories of dialogue in our search for a methodology for collaborative work in future cross-cultural ethnographic studies.
\end{abstract}

\section{Keywords}

classrooms, cross-cultural, dialogue, ethnography, families

\section{Introduction}

We come to every situation with stories, patterns and sequences of childhood experiences that are built into us. Our learning happens within the experience of what important others did. (Bateson, 1979: 13)

The story below comes from a diary of work conducted with mothers and their children during the 1980s. The primary school where it took place was in Canning Town, the area that used to be the centre of the London Docks. I (EG) was told that a large number of children were experiencing severe literacy difficulties; these were interpreted by the school as a result of a lack of confidence

\section{Corresponding author:}

Eve Gregory, Centre for Language, Culture and Learning, Goldsmiths, Lewisham Way, London SEI 4 6NW, UK Email:eds0I@gold.ac.uk 
of the parents, especially the mothers, in their own literacy skills. And so I set up a reading group where I helped mothers to read with their children. This is what I later wrote:

My first meeting with a group of five mothers both clarified and mystified the situation. Feeling somewhat like a jailor leading prisoners unwillingly to their cell, as we made our way down the corridor to the parents' room, one mother from behind said quietly: 'You won't want us to use our brains, will you?' Another laughed nervously and said, 'Yes, our brains are dead, you see. We're alright for a bit of cleaning or polishing, but don't ask us to use our brains.' After such an inauspicious start, our first meeting was little short of a disaster. I tried to establish a shared background. After all, I myself came from an extended East End family and my uncle had worked all his life in 'their' dock (without the coveted dockers' ticket), but immediately did the wrong thing by pulling out an article from 'The Times Educational Supplement' on the importance of family involvement in reading. Brenda nudged Gloria: 'Innit funny the way them educated people always read The Times', she said, and my enthusiasm tailed off into sheer embarrassment. (Gregory, 2005: 3)

Ethnographers try to interpret events from the perspective of their participants rather than from their own point of view. This is often referred to as making 'emic' rather than 'etic' interpretations (Geertz, 1973; Schieffelin and Ochs, 1986). However, such a task is easier said than done. As we begin to see above, stories and patterns of events brought to situations by researchers and researched are likely to be very different. This is particularly the case when each has a different social, cultural or linguistic background and a very different life trajectory. Even if a common heritage is shared, only the researcher might convince herself of a mutual empathy, solidarity or interest. The researched, as we see above, is far more likely to perceive the distance of the present than the proximity of the past. Cross-cultural studies and those where there is a clash of social class often involve participants from very different backgrounds where the researcher cannot be an 'Insider' to all. But even 'Insiders' have their own problems, as we shall see below.

Over the past decade, we (the authors) have worked together on a series of ethnographic projects to investigate the home and community literacies ${ }^{1}$ taking place in both Bangladeshi British and Anglo communities living in east London. These have focused not only on the role played by parents but also the involvement of siblings and grandparents and, most recently, faith activities in introducing and promoting literacy learning. In this article, we unravel, as honestly as we can, the difficulty of being researchers in the homes and classrooms of young children and their families whose origins are, in one case, very different and, in the other, more similar to our own. ${ }^{2} \mathrm{We}$ do this through a series of vignettes typifying the dilemma of both the 'Outsider' and the 'Insider' role. These 'stories' highlight paradigmatic moments of complexity, clashes or collusion which we then unpick in terms of their generalizability for others working in the field. Following an outline of the theoretical framework underpinning our understanding of how young children learn, the article comprises two parts: first, the 'Outsider' and second, the 'Insider' dilemmas which represent different yet equally challenging demands. Finally, we extend Bahktin's concept of 'dialogue' (1986) to offer an alternative way of interpreting our vignettes and consider some proposals for collaborative work in future cross-cultural ethnographic studies. ${ }^{3}$

\section{Theoretical framework and background}

Crucial to our work on family and community literacies have been studies across different disciplines arguing for learning to be viewed as a sociocultural phenomenon; in other words, studies that view our 'stories' as the result not just of our personal and interpersonal relationships, but the social, cultural, historical and political circumstances in which we grow up and live. Thus, 
Vygotsky's writings $(1962,1979,1981)$ both provided a starting-point and have underpinned all our work:

Any function in the child's development appears twice, or on two planes. First it appears on the social plane, and then on the psychological plane. First it appears between people as an interpsychological category, and then within the child as an intrapsychological category ... (Vygotsky, 1981: 163)

Inspired by Vygotsky, researchers from different disciplines have fleshed out and extended our understanding of the relationship between cognition, the personal and the sociohistorical context in which we live. Cultural psychologists such as Cole (1996) focus on the intimate link between mind or thought processes and culture, showing how mind is interiorised culture and culture is exteriorized mind. His work also examined and extended our understanding of prolepsis or ways in which the caregiver, often the mother, looks backward into her own past in order to project forward to her child's future - a process deeply embedded in culture and history. Others have detailed the finely-tuned scaffolding provided by caregivers within the 'curriculum' of their own culture (Dunn, 1989; Wood et al., 1976). 'Scaffolding' has been further refined to afford a greater role to the child her or himself, using the term guided participation (Rogoff, 1990, 2003). Studies on 'scaffolding' and 'guided participation' underpinned our argument for the synergy taking place between siblings where the younger sibling acts as an adjuvant to the older child's learning which takes place equally on both sides (Gregory, 2001; Gregory and Williams, 2000).

Studies into early socialization in cross-cultural contexts have been particularly helpful to our work since they dispel myths of a 'universality' of child-rearing across continents, including a universality of literacy practices. These studies argue strongly for the ideological nature of language, literacy and learning practices, showing, for example, how literacy practices develop for different purposes and are equally suited for the task in hand, in spite of being rated differently by society (Barton and Hamilton, 1998; Heath, 1983; Scribner and Cole, 1981; Street, 1984). Others contrast the socialization of children in Western and traditional societies, showing that children and caregivers across the world do not interact within one 'biologically defined choreography' (Stern, 1977) but many choreographies between and within societies. Heath (1983), Keller et al. (2002), Nsamenang and Lamb (1998), Rogoff (1990, 2003), Schieffelin and Ochs (1986) and Super and Harkness (1982) all depict contrasting ways of childrearing and the different expectations of both children and caregivers in different cultures, revealing the danger of assuming common beliefs across cultures. Schieffelin and Ochs (1986) use the helpful notion of 'cultural repertoires', which differ considerably in traditional and Western cultures.

A separate and important area of sociocultural studies for our work has been that focusing on syncretism. With their origins in the syncretism of European and African religions in the Caribbean, more recent studies on syncretism understand the concept as the dynamic mingling of cultures, languages or activities (Volk with de Acosta, 2004). Like work by Giroux (1992), Brooker (2002), Duranti et al. (1995), González (2005) and Kenner (2004) and our findings reveal complexities, contradictions, tensions and richness alongside disparities of power between teachers and families and families and researchers. Developing from this work, we have collected studies which we term Syncretic Literacy Studies (Gregory et al., 2004) where we show how children acquire membership of different cultural, language and literacy groups in different contexts or domains of their lives. As Kenner argues, young children have the remarkable ability to live in 'simultaneous worlds' (Kenner, 2004: 55).

The framework presented above has underpinned our analyses and interpretations of young children's learning in studies over the past 15 years. ${ }^{4}$ Young children learn within the context of 
their close families and their communities as we see clearly above. The studies in our theoretical framework above do not, however, help us in understanding how to interact with the older generation (teachers, parents) whose beliefs may or may not sit easily with our own. In the vignettes presented below, we show how researching these practices will involve a constant questioning of assumptions on the part of the researcher. On speaking more recently on the future of ethnography and its parent discipline anthropology, Geertz refers to the way in which it is 'moving raggedly on', reflecting the wider world of fragmentation, dispersion, pluralism, disassembly and contradictions (2002: 8). This 'ragged' notion of ethnography is highlighted through our vignettes below which, presented chronologically, reflect the collusions, challenges and clashes (resulting sometimes in near catastrophes) in our work to the present day. We first offer four vignettes presented chronologically to illustrate the dilemma facing the 'Outsider' followed by one detailed episode revealing issues confronted by the 'Insider'. We then go on to outline the possibility of extending Bakhtin's (1986) notion of 'dialogue' to underpin our methodology in future crosscultural research.

\section{The 'outsider's' dilemma}

We begin with the story of Tony in an inner-city school in middle England during the mid-1980s. Influenced strongly by two major government reports in education, the Plowden Report (1967) and the Bullock Report (1975), a number of teachers at this time had turned their back on behaviourist approaches to teaching and learning (Skinner, 1957) and were following a curriculum referred to as 'child-centred'. A key concept for this curriculum was that of provision; young children were provided with exciting resources such as wet and dry sand, water, construction toys, dressing-up materials for socio-dramatic play as well as excellent books, art and other writing materials and were encouraged to experiment with them (Kelly, 1955). ${ }^{6}$ Of course, teachers knew what concepts and language they wanted children to learn and this was carefully planned through their provision. Nevertheless, these aims were often implicit to families and would be discovered by children themselves through play. The vignette below was taken from field-notes made at the time.

Into this scenario I (EG) stepped as a recent teacher, now a new College lecturer and teacher educator, aiming to research how young children of different linguistic, cultural and social backgrounds stepped into learning to read at home and in their first year at school. One of the children in my group was Tony, at four, the oldest child of parents and grandparents of Chinese origin who managed a 'take-away' restaurant nearby. During his first few weeks of school, I visited Tony's home to explain my research. His family was warm, welcoming and interested. They were highly ambitious for their oldest son who had already started attending Chinese Saturday school. However, Tony's classroom was revealing a different story. Tony seemed unable to 'choose' his activity, participate in sociodramatic play or experiment with writing, preferring instead to repeat word for word after the teacher or to copy exactly illustrations or print from his book. His teacher and I discussed his lack of progress and I took his family a beautiful dual language (Mandarin/English) book. When Tony's father and grandfather looked askance at the book and put it on top of a high cupboard (their earlier warmth having distinctly chilled), I was equally shocked. My explanation of events to Tony's teacher led to her instinctive response: 'Maybe I ought to give him more structure, cards with words on them to take home in a tin, or something like that, but it goes against my child-centred approach to teaching.' As a teacher, I understood exactly what she meant. Such an approach would have been overly structured at the time and strictly not recommended. Yet in my role as researcher, I was struck by the paradox revealed in her words. What did 'child-centred' actually mean? 
This event led to months of embarrassment and years of reflection on my part. Surely, Tony's love of repetition, neat copying and ordered work (shown clearly in his practice sheets from his Saturday school) meant that this was, indeed, his way of learning and to follow this would have been "childcentred' for him? As teachers, however, the term had come to mean the way we thought children should learn. Rather than seeing that 'child-centred' would inevitably mean something different according to children's cultural background, we were slotting them into our own cultural mould. This sudden realization left me with a deeply uncomfortable dilemma. As an 'Insider' to the teaching profession, I found it difficult to question the teacher's words since I felt I would be betraying a conscientious colleague. Yet ignoring what she said would mean a betrayal of Tony and his family, the other participants of my study. From then on, the research presented complex 'Insider/ Outsider' dilemmas. Visits to the family became increasingly difficult, as no matter how much I claimed impartiality, I was seen as a representative of the school, distinctly one of 'them' (London, 1903) as opposed to one of 'us'. Talking to the teacher became equally hard, since I realized that I was no longer seen to 'support' but rather to criticize her - thus betraying my profession. In-service sessions to groups of practising teachers became hardest of all, since I was viewed as placing myself in a philosophical and political position linked to behaviourism - quite the opposite of how I saw myself or wanted to be seen.

It seemed that in-depth ethnographic work into the scope and nature of children's home and community literacy practices would be the most appropriate way of documenting what actually does count as important in family literacy lives. Studies from the US were already revealing a wide variety of language and literacy practices taking place within families of different social and cultural backgrounds (Heath, 1983). However, until the last decade of the 20th century, we knew almost nothing in Britain of the language or literacy practices of children from different cultural, linguistic or even social backgrounds.

During the mid-1990s, ${ }^{7}$ our research team began to study the family literacy histories and children's learning in Bangladeshi British and Anglo (indigenous, mother-tongue English) families in East London and to compare young children's (five- to six-year-olds) strategies as they set about learning to read with both their parents and teachers. Of course, I (as a mother-tongue English speaker of white Anglo background) realized that I could not be an 'Insider' to both the Bangladeshi British and Anglo families. A Bangladeshi British researcher who was familiar with the local community was to be my mediator (see Baynham, 1995, for a detailed explanation of the role of the 'mediator'). Yet I had still not quite anticipated the scope of my difficulties and the serious nature of the 'faux pas' I would make as an 'Outsider'.

The event below took place at the beginning of the project outlined above. The researcher and I had agreed to purchase different artefacts to assist our In-service education sessions with teachers, enabling them to increase their knowledge on the community literacy practices of their Bangladeshi British children.

The setting is a narrow, inner-city 'lane' in East London with various shops which provide for the local Bangladeshi community. The warm, sunny day makes this busy area friendly, even though a predominantly male population is seen frequenting the stores. Nasima and Eve have decided to buy a Qur'ān to add to their collection of materials for their project. Among the various food, clothes and music/book shops, they enter one which displays these holy books and other wares in its windows. On entering, a bearded man wearing a holy cap, nods and looks away. The two visually absorb the goods around them. The shop space is fully utilised, with shelves full of Arabic and Bengali books rising high above their heads. It looked like 'Aladdin's cave' with amulets, rosary beads and prayer mats decorating the walls and tables. The Qur'āns on show are beautifully embossed with gold Arabic lettering, in all shapes and sizes. Their 
eyes fall on one of the larger ones. 'Shall we take a look at that one?' asks Eve, as she points to a large green one. 'If you like,' replies Nasima. 'You are going to get it if we decide to buy it?' she continues awkwardly. 'What do you mean?' wondered Eve. 'You are going to hold it?' she says more specifically. 'I will if there's a problem, but why?' queries Eve. 'Well I can't hold it!' cries Nasima. 'Why, what's wrong with your hands?!' After which, Nasima explained that the washing of the body is essential before touching the Qur'ān, or one will be damned . . However, they were able to get the book wrapped before leaving the shop. (Gregory, 2008: 27-28)

Through lack of knowledge and incompetence, my 'Outsider' role had established itself in the most everyday activities. I had assumed that buying a Qur'ān would be no different from purchasing a Bible. Similarly, Nasima (my colleague and researcher on this project) of Bangladeshi origin had assumed that I would be aware of the reverence with which Muslims treat the Holy Book, hence the need to undertake 'wazu' (the washing ritual) before touching it. After all, I had been teaching and working with Muslim families for many years when the shopping incident described above occurred. The purpose of telling this story is to underline how easy it is wrongly to assume that we share common understandings and interpretations even with colleagues.

A little later on in the project, I visited our participating parents with Nasima. We aimed to talk about their own literacy history as well as their views on their children's reading at home and in school.

It was our last visit for that particular day. We had seen Mrs Ahmed a few days earlier and she had agreed to take part in the work. As we expected, she was at home, waiting for the children to return from school. She invited us to sit down and chatted for a few minutes to Nasima, the research officer. The outcome was disappointing.

'Unfortunately, Mrs Ahmed can't talk to us today, because she has to take a bath.'

I picked up my things to go.

'But she asks if we would like a cup of tea.'

I accepted, and whilst she was in the kitchen whispered:

'If she has enough time to drink tea with us, couldn't she talk about her children's reading as well?'

'But you don't understand', replied Nasima, surprised. 'She's just finished her housework and she feels dirty. Reading is very important for her. She wants to feel properly prepared by washing and changing her clothes.' (Gregory, 1996: 91)

Again, I felt jolted into examining the assumptions I was making of other cultural groups on the basis of my own interpretations and experiences.

The final mistake made was the most significant in that it could have changed the whole study and led to quite disastrous and unfair results. Below is an excerpt from my diary, written at the time:

I had expected the Anglo and Bangladeshi British group of parents to participate in very different literacy practices with their children. Yet I had not anticipated that the Bangladeshi British parents might not read at all with their children at home. When Nasima reported that she was unable to tape parents and children 
reading together because it simply did not happen, I first thought she must be lacking in observation. ${ }^{8}$ Yet I knew her work was too thorough for this. Finally, panic set in at the idea of having no data to present to the funders (the Economic and Social Research Council) and, throwing ethnographic principles to the wind, I was on the point of telling Nasima 'Well, simply ask them to do something then!' Her quiet response was so self-evident and I was shocked by my own lack of insight as an 'Outsider' when she said, 'But the older siblings are reading all the time with the younger ones'.

Nasima went on to collect quite unique detailed and extensive data that led to a future ESRC funded study on the role of siblings in young children's language and literacy development. With hindsight, it was so obvious to the 'Insider' that parents whose English was very limited would leave any literacy interaction to older siblings who were in a far better situation to 'tutor' the younger children both in English and Bengali where classes were attended by siblings together.

All the examples in this section of the article show clearly the importance of the 'Insider' as a mediator of language, knowledge and cultural insights into the practices of a community. However, 'Insiders' are not without their own dilemmas as we see below. The second part of this article passes to the very different but equally challenging role when 'Insiders' become researchers in very familiar groups and settings.

\section{The 'insider's' dilemma}

My (MR) experience as an ethnographer started with an ESRC funded research project involving grandparents and their interaction with their grandchildren. ${ }^{9}$ I then went on to become a researcher on two other projects which were ethnographic in nature. ${ }^{10}$

In all these situations I considered myself an 'Insider' by being a Bangladeshi as well as being Muslim. My initial feelings as soon as I received the offer of my first post as a researcher was one of exhilaration and anticipation as I knew I would be working amongst my 'own' people sharing a similar background, culture and faith. I was to job-share with a fellow Bangladeshi researcher Tahera, who was also female, a little older and coincidently happened to be my sister unbeknown to the interview panel! We both talked and discussed our roles in this project as researchers, being siblings and how all of this might have an impact on the project. Our initial feelings were that it would be a simple process, as gaining 'access' would not prove to be a problem because we both would be able to 'talk and walk' our way into the homes of our participants without any difficulty. This soon proved to be more difficult than we had anticipated.

As researchers on the grandparents project one of our initial tasks was to find out the children who had grandparents, and as a team we decided the best way to do that would be to send questionnaires home followed by a coffee morning for those that responded. Through this process we would be able to choose our 'focus' families. The questionnaire required drawing up a list of activities that we felt the grandparents would be engaged in with their grandchildren. Here being an 'Insider' helped as we were able to add some questions that were culturally specific and 'we felt' would be common amongst the Bangladeshi families. We then translated the questionnaires into Bengali. The next stage was based within the school where we both spent time with the children in their classrooms. Once the questionnaires were returned and we were sure no more would come in we started preparing for the coffee morning. Both my co-researcher and I felt extremely confident that our presence at the beginning of the day and the interaction we had with the families in the playground at the end of the day would 'naturally' draw in 'all' the grandparents we interacted with. We felt we had managed to convey to them the importance of the research as well as creating some excitement. On the day of the coffee morning the turnout was not what we both had expected. 
A few grandparents had turned up keen and eager but not the number we expected. Building a rapport with the community was simple but once it transpired that I was going to be a researcher within their homes the perception changed, and every time I felt an invisible wall would be put up. The following vignette taken from my field-notes expresses the 'dilemmas of an Insider'.

In early December 2004 I made my first visit to the home of Sumayah's paternal grandparents. I packed my equipment, making sure everything was in working order, the camcorder, minidisk, and my notebook. When I looked at my bulging bag I wondered if it was the right thing to do on my first visit, what if they were put off by the size of the bag. But then again what if I miss an opportunity by not taking anything with me? I battled with my thoughts and decided to take everything and make my way to the house. I was exhausted by the time I found their house, as I needed to walk most of the way. Once at the door I collected my nerves and decided what I was going to say. To my relief Sumaya's mum opened the door welcoming me into the house. Sumaya who also came to the door to receive me took me up two flights of stairs into the living room. Once in the living room I was left alone while they both went to bring the grandparents. This gave me an opportunity to rove my eyes around the room. There were wall hangings that had Bengali poems with hand embroidered flowers on them. Most of the wall hangings portrayed images of Bangladesh and a large plasma TV adorned one side of the room with Bangla blaring from the S Channel. Sumaya walked in with her grandmother and grandfather and showed them where to sit and she sat between them. We greeted each other with the Arabic greeting 'Assalamualikum' (peace be with you). No-one spoke for a little while, both grandparents were diverted by the TV and Sumayah was talking to her cousin brother (first cousin) who had also walked into the room. I sat quietly waiting for the right moment to explain my presence and build a rapport with them. This moment arrived when Sumayah's mum entered and introduced me to them in Bengali. She expressed that I had come to 'speak' to them about them as grandparents. She also took the liberty of turning the TV off and left the room. When all eyes were on me I began to explain the research and kept emphasizing how we important we thought grandparents were and how we wanted to raise this profile by highlighting the activities that they do with their grandchildren. I felt I was babbling because neither grandparent contributed to the discussion, nor did they show much interest, the only question asked was related to who 'wanted' this information. Although I tried to explain, I felt they were not very convinced. I decided to turn my attention to Sumayah and asked her what activities she did with her grandparents. She jumped at the chance and started talking about all the things she does with them. Throughout our chatting she looked at her grandparents, hugging them, smiling at them and looking for approval. This banter drew from them smiles and nods.

After a good two hours I decided it would be best to leave and come back another day as I was left talking to Sumayah only and both grandparents had left the room saying they had things to do. I however left with many questions whizzing through my troubled mind. I expected to do so much yet came away feeling I had not impressed the grandparents at all. Was it because I had not come across confident enough? Did I talk too much? Did I come across too young and unreliable? Would it have helped if Tahera or our supervisors who are white academics were there? I felt disheartened at the fact that before entering the home I felt I was an 'Insider' but I left feeling very much a 'confused Insider'. Here began my journey to unravel what it means to be an 'Insider' and in whose perspective. This initial experience made me think about my position as a researcher and 'who' I am trying to 'serve', the research or the community. My desire was to empower voices within my traditionally marginalized community as I felt that their voices are not often heard. However, I began to realize that this will not always be shared by community members if they feel that I am being 'used' to 'gather' information to 'expose' the community. This highlighted the fact that even though externally I fit the criteria to be an 'Insider' I still had to build trust and confidence between 
myself and the participants similar to being an 'Outsider' because I am entering as an ethnographer into a 'protective' area of a family and their lives.

\section{Looking back and ahead:The notion of dialogue}

A crucial question arising from all the vignettes above is: how might we begin to find a way out of the 'Insider/Outsider' dilemma and authenticate our research? We started this article by referring to the intrinsic aim of ethnography to present 'emic' interpretations (seeing events from the participants' point of view). We then went on to unpick the almost insoluble dilemmas of this when working in cross-cultural contexts. Briefly, we showed how: a) we cannot be both 'Insider' and 'Outsider' at the same time. Indeed, even if our own background or heritage bears similarity with those of the participants, the fact of being a researcher itself makes us different; $b$ ) whatever type of research is conducted, funders will clearly not accept anything but a well-designed proposal. Simply to say that we want to 'find out what is going on in a community' or that 'if it doesn't happen we'll change our approach' is not enough. Consequently, we often feel the need to hypothesise what is likely to take place in order to have the resources (i.e. funds) to investigate it. These hypotheses may well end up not reflecting what participants actually do or believe. Thus, if we do not either abandon or change them we do not fulfil our aim of producing emic interpretations at all.

As a result of this, we are beginning to shift our original aim of producing emic interpretations of events (i.e. interpretations from the participants' points of view) to that of 'giving a voice to those people whose voices would otherwise not be heard' (Erikson, 1999). ${ }^{11}$ The crucial question is how we go about doing this, since we still need to select from the participants' own words - and this selection will inevitably ultimately be our own. Although not written as offering practical ideas on methodological issues, Bakhtin's (1986) work gives us a way forward through his notion of the 'dialogic self'. Bakhtin views the self as a changing entity, constantly engaged in a dialogue. All language, says Bakhtin, is inherently dialogical as individual consciousness lies on the borderline between the self and another. The word in language is half someone else's. It becomes 'one's own' only when appropriated with intention. Crucially, each word contains, within itself, diverse, discriminating and often contradictory components. A dialogue thus becomes a model of the creative process. This understanding also extends to culture itself:

In the realm of culture, outsideness is a most powerful factor in understanding . . A meaning only reveals its depth once it has encountered another foreign meaning ... We raise new questions for a foreign culture, ones that it did not raise for itself; we seek answers to our questions in it, the foreign culture responds to us by revealing to us its new aspects and new semantic depths. (Bakhtin, 1986: 7)

Indeed, for Bakhtin, 'outsideness . . . and a love for difference are the first pre-requisites for creatively understanding another person or another culture and for being creatively understood by them' (Emerson, 1996: 110). A dialogic view of language and culture thus inherently entails being responsive to others and sees the act of authoring as a creative answerability and responsibility.

How might these ideas inform our understanding of our vignettes presented above? The value of Bakhtin's notion of dialogue is, perhaps, best illustrated by the vignette of Tony, close to the beginning of this article. I (EG) was not aware of the deep-seated paradox in my own beliefs on 'child-centredness' until they were revealed by Tony and his family. In other words, I could not notice the contradiction in my cultural beliefs as a teacher until I gained insight into the culture, values and knowledge of another culture - in this case, that of a Chinese-British family. Through 
Tony and his family I became more aware of myself in my role as a researcher and more outside my beliefs as a teacher. In so doing, I was later able to discuss Tony and similar children with other teachers who also gained an understanding into the situation of similar children in their classes. In this way, a process of enrichment could take place, where both sides (teachers and researcher) joined in an inseparable dialogue. Through the teachers' insights, families such as Tony's were given a potential voice in their children's schooling. Bakhtin's ideas have also been recently taken up by ethnographers recognising the important role of reflexivity in research which 'acknowledges that the orientations of researchers will be shaped by their sociohistorical locations' (Hammersley and Atkinson, 2007: 15) and those working with autoethnography who interpret a dialogic view as being responsive to the voices of others and a necessary 'double-voicing' (dialogism) in re-authoring the self and others (Ellis, 2004; Maguire, 2006).

Finally, we have just embarked on a major study of young children's language and literacy learning in faith settings where Bakhtin's views on dialogism are invaluable. The faiths chosen are Christianity (Catholic and Pentecostalist), Islam and Hinduism and the families are 'new Londoners' from Poland, Ghana, Bangladesh and India. ${ }^{12}$ Within the first month, a number of dilemmas have been encountered by both the 'Outsiders' (the researchers who, in all but one case do not share the language, culture or faith studied) and the 'Insiders' (the research assistants who do share language, culture and faith of the participants). The 'Outsiders' are complete novices when it comes to the rituals, gestures, language and behaviour patterns of the faith group. They are often embarrassed by the number of 'why?' questions they have as well as the 'faux pas' they make. As members of the faith group, the 'Insiders' are extremely uncomfortable at both the thought of note-taking rather than praying during faith activities and of asking other members of the faith group what seem to be obvious (and, by implication, disrespectful) questions. We are attempting to tackle these dilemmas in the following way: i) by recognizing the inevitable, that is, that one cannot be an 'Insider' and 'Outsider' simultaneously; ii) by 'pairing' an 'Insider' with an 'Outsider', that is, researcher and research assistant who observe and discuss their observations together; iii) by inviting 'pairs' from the other faith research communities to also visit, observe and discuss their own faith group; iv) by holding fortnightly meetings of the whole team to discuss similarities and differences across and between faith groups.

Our discussions and dialogues about faith in our new project are revealed in our 'field-narratives' (the BeLiFS team, 2010) as we visit different settings. As Amoafi (our Ghanaian researcher in the Pentecostalist Church) observes the Sunday School teachers, she reassures them of the importance of their work. This is yet further confirmed by the enthusiasm of our researchers from the other faiths. But it is ultimately confirmed by inviting councillors and/or teachers or other representatives from mainstream schools or Education Authorities to recognize and learn from their work. In this way, we might begin to step beyond concerns of being 'Insider' or 'Outsider' to working with rather than in parallel to our participants.

\section{Notes}

1. We use the term 'literacies' to refer to the different literacy practices in which children and adults participate in different sites and with different community groups. For a fuller discussion on this, see, for example, Heath and Street with Mills (2008).

2. We shall use the terms ' $I$ ' to refer to vignettes and comments referring the first author (EG) or the second author (MR) when relevant; otherwise we use 'we' more generally in the article to present our common views. Our article thus comprises two stories within a bigger story of shared beliefs and collaborative work.

3. 'Becoming literate in faith settings: Language and literacy learning in the lives of new Londoners', ESRC funded project (2009-2012) (RES-062-23-1613). 
4. ESRC R000 222487 'Siblings as mediators of literacy in two East London communities' (Gregory E) 1998-1999. ESRC R000220131 'Intergenerational learning between grandparents and young children in East London' (Kenner C, Gregory E and Jessel J) 2002-2003.

5. 'Child-centred' education. See Blenkin and Kelly (1987).

6. Often referred to as a 'constructivist' theory of learning. Kelly's work (1955), referring to us all as 'scientists', learning through experimentation with both language and activities and either slotting findings into our grand schema of events or rejecting them.

7. ESRC R000 221186 'Family literacy history and children's learning strategies at home and in school' (Gregory E and Mace J) 1994-1996.

8. This was rather similar to the experience recounted by Schieffelin and Ochs (1986) during work with Kaluli parents. The initial research project set out to investigate language and socialization patterns between infants and their mothers. Upon arrival, the researchers discovered that mothers did not converse with their infants before the child could talk and that care-giving was left mainly to older siblings.

9. ESRC funded study R000220131 'Intergenerational learning between grandparents and young children in east London' (Kenner C, Gregory E and Jessel J) 2003-2004.

10. ESRC funded study RES-062-23-1613 'Becoming literate in faith settings' (Gregory E, Jessel J, Kenner C, Lytra V and Ruby M) 2009-2012 and ESRC funded study R000 221528 'Bilingual learning in mainstream and community contexts' (Kenner C and Gregory E) 2006-2007.

11. Erikson (1999). His exact words were: 'Ethnography makes visible the lives of those whose lives are not normally told.'

12. RES-062-23-1613 'Becoming literate in faith settings: Language and literacy learning in the lives of new Londoners (Gregory E, Jessel J, Kenner C, Lytra V and Ruby M) 2009-2012.

\section{References}

Bakhtin MM (1986) The Dialogic Imagination, trans. Holquist M and Emerson C. Austin: University of Texas Press.

Barton D and Hamilton M (1998) Local Literacies: Reading and Writing in One Community. London: Routledge.

Bateson G (1979) Mind and Nature. London: Wildwood House.

Baynham M (1995) Literacy Practices. London: Longman.

BeLiFS team (Gregory E, Jessel J, Kenner C, Lytra V and Ruby M with Choudhury H, Kwapong A, Llankuberan A and Woodham M) (2010) Team meeting discussion, January, 2 April.

Blenkin G and Kelly VA (1987) The Primary Curriculum: A Process Approach to Curriculum Planning. London: Harper and Row.

Brooker L (2002) Starting School - Young Children Learning Cultures. Buckingham: Open University Press. Bullock Report (1975) A Language for Life. London: HMSO.

Cole M (1996) Cultural Psychology: A Once and Future Discipline. Cambridge, MA: Harvard University Press. Dunn J (1989) The family as an educational environment in the pre-school years. In: Desforges CW (ed.) Early Childhood Education. The British Journal of Educational Psychology. Monograph Series No. 4. Edinburgh: Scottish Academic Press.

Duranti A, Ochs E and Ta'ase EK (1995) Change and tradition in literacy instruction in a Samoan American community. Educational Foundations 9(4): 57-74.

Ellis C (2004) The Ethnographic I: A Methodological Novel about Autoethnography. New York: AltaMira Press. Emerson C (1996) Keeping the self intact during the culture wars: A centennial essay for Mikhail Bakhtin. New Literacy History 17(1): 107-126.

Erikson F (1999) Plenary at The Ethnography Forum, University of Pennsylvania, Philadelphia, 1 March. Geertz C (1973) The Interpretation of Cultures: Selected Essays. New York: Basic Books. 
Geertz C (2002) An inconstant profession: The anthropological life in interesting times. The Annual Review of Anthropology, available at: http://anthro.annualreviews.org, accessed 20 November 2009.

Giroux H (1992) Border Crossings: Cultural Workers and the Politics of Education. New York: Routledge.

González N, Moll L and Amanti C (2005) Funds of Knowledge: Theorizing Practices in Households, Communities and Classrooms. Mahwah, NJ: Erlbaum.

Gregory E (1996) Making Sense of a New World: Learning to Read in a Second Language. London: Paul Chapman and SAGE.

Gregory E (2001) Sisters and brothers as language and literacy teachers: Synergy between siblings playing and working together. Journal of Early Childhood Literacy 1(3): 301-322.

Gregory E (2005) In: Conteh J, Gregory E, Kearney C and Mor-Sommerfield A (eds) On Writing Educational Ethnography: The Art of Collusion. Stoke-on-Trent: Trentham.

Gregory E (2008) Learning to Read in a New Language: Making Sense of Words and Worlds. London: SAGE.

Gregory E and Williams A (2000) City Literacies. London: Routledge.

Gregory E, Long S and Volk D (2004) Syncretic literacy studies: Starting points. In: Gregory E, Long S and Volk D (eds) Many Pathways to Literacy: Young Children Learning with Siblings, Grandparents, Peers and Communities. London: Routledge.

Hammersley M and Atkinson P (2007) Ethnography: Principles in Practice. London: Routledge.

Heath SB (1983) Ways with Words. Language and Life in Communities and Classrooms. Cambridge: Cambridge University Press.

Heath SB and Street B with Mills M (2008) On Ethnography: Approaches to Language and Literacy Research. New York: Teachers' College Press.

Keller H, Yvosi RD and Voelker S (2002) The role of motor stimulation in parental ethnotheories. Journal of Cross-Cultural Psychology 33(4): 398-414.

Kelly G (1955) A Theory of Personality. Cambridge, MA: The Norton Library.

Kenner C (2004) Living in simultaneous worlds: Difference and integration in bilingual script learning. International Journal of Bilingual Education and Bilingualism 7(1): 43-61.

London J (1903) The People of the Abyss. New York: Macmillan.

Maguire MH (2006) Autoethnography: Answerability/responsibility in authoring self and others in the social sciences/humanities. Review essay: Carolyn Ellis (2004). The Ethnographic I: A Methodological Novel about Autoethnography [25 paragraphs]. Forum Qualitative Sozialforschung/Forum: Qualitative Social Research 7(2), Art. 16. Available at: http://www.qualitative-research.net/fqs-texte/2-06/06-2-16-e.htm, accessed 12 April 2009.

Nsamenang AB and Lamb ME (1998) Socialization of Nso children in the Bamenda Grassfields of Northwest Cameroon. In: Woodhead M, Faulkner D and Littleton K (eds) Cultural Worlds of Early Childhood. London: Routledge.

Plowden Report (1967) Children and their Primary Schools. London: HMSO.

Rogoff B (1990) Apprenticeship in Thinking. New York: Oxford University Press.

Rogoff B (2003) The Cultural Nature of Human Development. Oxford: Oxford University Press.

Schieffelin B and Ochs E (1986) Language Socialization across Cultures. New York: Cambridge University Press.

Scribner S and Cole M (1981) The Psychology of Literacy. Cambridge, MA: Harvard University Press.

Skinner J (1957) Verbal Behavior. Acton, MA: Copley Publishing Group.

Street BV (1984) Literacy in Theory and Practice. Cambridge: Cambridge University Press.

Stern D (1977) The Interpersonal World of the Infant: A View from Psychoanalysis and Developmental Psychology. New York: Basic Books.

Super CM and Harkness S (1982) Cultural Perspectives on Child Development. Oxford: W.H. Freeman. Vygotsky LS (1962) Thought and Language. Cambridge, MA: MIT Press. 
Vygotsky LS (1979) Mind in Society. The Development of Higher Psychological Processes. Cambridge, MA: Harvard University Press.

Vygotsky LS (1981) The genesis of higher mental functions. In: Wertsch JV (ed.) The Concept of Activity in Soviet Psychology. Armonk, NY: Sharpe.

Volk D with de Acosta M (2004) Mediating networks for literacy learning; The role of Puerto Rican siblings.

In: Gregory E, Long S and Volk D (eds) Many Pathways to Literacy: Young Children Learning with Siblings, Grandparents, Peers and Communities. London: Routledge.

Wood D, Bruner J and Ross G (1976) The role of tutoring in problem solving. Journal of Child Psychology 17: 89-100.

\section{Author biographies}

